\title{
Building an Automated Win-Win Negotiation Process Model
}

\author{
Latifa Ghalayini ${ }^{1} \&$ Dana Deeb ${ }^{2}$ \\ ${ }^{1}$ Lebanese University, Faculty of Economic Sciences and Business Administration, Lebanon \\ ${ }^{2}$ Lebanese University, Doctoral School of Law, Political, Admin and Economic Sciences, Lebanon \\ lghalayini@hotmail.com,danahdeeb@gmail.com
}

\begin{abstract}
This paper builds an automated negotiation process model for integrative negotiations. The process model defines and automates the necessary phases and activities along with the integrative negotiation approach principles to create win-win outcomes that mutually satisfy negotiating parties. However, to realize this objective, the negotiation literature and theories are reviewed to determine the relevant theories for integrative negotiations that help to develop and form the basis of the process model. After investigation, it became evident that three main theories, which are Decision Theory, Rational Choice Theory and Mutual Gains Theory, contribute to building the integrative process model by setting its phases and components. The model is composed of five main phases with several sub-phases. Decision theory with mutual gains theory provides the robust process model through several phases, and rational choice theory with mutual gains theory ensures they are implemented in a fair, objective manner to come up with a satisfying win-win solution. Hence, automated negotiation processes when designed in a robust manner that is based on the theory that serves integrative approaches could lead to win-win negotiation outcomes. The foundation of the win-win negotiation process model contributes to designing win-win negotiation outcomes through structuring automated negotiation and setting its phases along with the integrative negotiation principles. It develops the negotiation field by integrating automation and the integrative approach principles in a process model.
\end{abstract}

Keywords: Negotiation, Automated Negotiation, Integrative Negotiation, win-win Outcome, Negotiation Process Model.

\section{Introduction}

Negotiation exists in many forms all along with human life. Every human being negotiates at some point in his life, whether, at home, at work, at the market, etc. People use negotiation as an interaction tool to realize their needs. Negotiation is used by people, organizations, countries and even nations. It is "a basic means of getting what you want from others, a back-and-forth communication designed to reach an agreement when you and the other side have some interests that are shared and others that are opposed" (Fisher \& Ury, 1981). It is the process to optimize the individual gain. Negotiation research developed principles and protocols that govern negotiation procedures and help to organize and structure the field. Regardless of the negotiation process followed or the research methodology adopted to design such processes, the aim of any exchange is always to attain gain, and this is achieved through negotiation. Each negotiating party pursues to maximize his gain. Gain distribution and negotiation outcomes are highly affected by the approach of negotiation followed. The traditional negotiation approach of using distributive strategies to reach agreements is strongly debated. Such strategies result in win-lose outcomes where one side gets the biggest benefit possible at the expense of the other. This could be profitable on short-term communication or one-time deals.

However, on a long-term basis where relationships and reputation contribute, other approaches are required. Integrative approaches use objective criteria, seek designing solutions of mutual gain, give importance to exchanging information and group problem solving (Lewicki, Barry, Saunders, \& John, 2003) to reach winwin outcomes and ending both sides satisfied. Such approaches involve negotiators working jointly to create win-win solutions. Negotiation is usually done face-to-face, but with the advancement of telecommunication, electronic negotiation (E-negotiation), which is another form of negotiation, emerged. In electronic negotiations, the interaction between the negotiating parties is computer-mediated. Each of the negotiation forms has its uses, merits and hurdles. In face-to-face negotiation, direct interactions are usually affected by the verbal and non-verbal cues of the negotiators involved. Such cues could serve to reflect the "true meaning" behind messages, thus result in better understanding and judgment. Face-to-face negotiation serves as a good means for the flow of information (Arunachalam \& Dilla, 1995). On the other hand, automation 
cannot be disregarded as it exists and is part of our world today. Consequently, and with the advancement of technology, electronic negotiation gained clear advantages.

It differs in that it is a direct process; the negotiators' personalities are separated from the issues to negotiate (Carmel, Herniter, \& Nunamaker, 1993). Moreover, it disregards differences between negotiators and offers a common base to negotiate where they interact on an equal status. The degree of automation in negotiation can range from a simple information search support to a fully automated negotiation process. On one hand, integrative negotiation approaches involve creating profitable options to come up with win-win solutions. To create and design such options, negotiators need good cognitive skills especially when the complexity of the situation increases and when time restricts it. The fact that the most intelligent, competent and unbiased people face challenges in creating or assessing such options, imposes looking for a substitute good crafter or a supporter, either to create such options or to ensure their goodness. Therefore, automating negotiation processes, whether partially or fully, seems an opportunity to design and craft negotiation solutions that are win-win and satisfy the needs of the negotiating parties, especially when relations are long-term and negotiation contexts are complex.

To automate negotiation and implement it using software, implementation requires explicitly defining and structuring the process. In negotiation research, there is no consensus regarding the number of negotiation stages (Lande, 2017). Some scholars argue that negotiation does not follow a specific sequence of stages (Gifford, 2007), another group defined negotiation stages, while others focused on "tasks" including assessing the situation, taking positions, making concessions, and closing the deal (Lewicki, Saunders, \& Barry, Negotiation, 2015). Electronic negotiation requires a "process model" and a "protocol" (Kersten \& Lo, 2003). A process model gives a structure to the negotiation through phases and activities assigned to them (Jennings, et al., 2001). There are no specific process models for e-negotiation (Braun, et al., 2006). Braun et al. (2006) adapted a model formed from Gulliver's eight-phase model (1979), and consists of five phases: the planning phase, agenda-setting and exploring the field, exchanging offers and arguments, reaching an agreement, and concluding the negotiation. Braun et al. (2006) specify and structures the negotiation process, regardless of the negotiation approach followed, and whether win-win outcomes are the aim or not.

However, integrative negotiations, which aim to create win-win outcomes, require specific activities and tasks to design or search for such outcomes. Integrative negotiation approaches use objective criteria, seek designing solutions of mutual gain, and give importance to exchanging information and group problem solving, and thus components and activities are different. Then, does automate negotiation processes through an integrative approach structured phases lead to win-win outcomes? And how negotiation theories help to set and automate such an integrative negotiation process model? This paper aims to build a negotiation process model for automated integrative negotiations. The second section of the paper describes the methodology followed to build the process model. The third section illustrates Braun et al. (2006) negotiation process model that is considered as a general model and not specifically built for integrative negotiations. Then, negotiation theories are overviewed in the third part to select the theories that serve integrative negotiations to form the base of the process model. The selected negotiation theories are thereafter detailed in sub-sections. Section four encompasses the development of the process model, with each of its phases detailed in a subsection and finally synthesizing the phases.

\section{Methodology}

Different theoretical perspectives contribute to the development of the negotiation field and several theories contribute to defining and setting the process. Regarding, the negotiation process model, there are no specific process models for e-negotiation (Braun, et al., 2006). Additionally, Braun's (2006) model is not specifically set for integrative negotiation approaches. To build the negotiation process model for automated integrative negotiations, the paper considers the qualitative method, starting with a literature review of negotiation theories to select the theories, which serve the integrative negotiation approach and adhere to its principles. However, the epistemological approach of this paper considers the positivism strategy. The model treats an automated negotiation process, which takes place over the web and through digital forms. Therefore, the ground of the problem is formed upon automating the process and thus following a scientific approach. Moreover, it proposes a solution for creating optimal win-win negotiation outcomes that are value-free and 
assessed through an objective proposition. The objectivity of the solution comes from automating the offers' assessment process that should be predefined and transparent without interfering with the subjectivity of the negotiators in the assessment.

\section{Braun's Model}

Braun et al. (2006) built a negotiation process model based on Gulliver's eight-phase model (1979). It consists of five phases:

- The planning phase includes the formulation of the negotiation problem. Several attributes are specified in this phase including issues and options as well as negotiators' objectives, preferences and reservation levels.

- Agenda setting and exploring the field encompass discussions among the negotiators regarding the problems involved. This might result in adding new issues and options or deleting previously set ones. Objectives, preferences and constraints might also be discussed, thus resulting in revising and reformulating the problem. Furthermore, negotiators' specific objectives and preferences might also change.

- Exchanging offers and arguments allows negotiators to explore their counter parties' limitations so identifying areas of disagreement. Compromises are realized in this stage and solutions are restricted to efficient ones that are acceptable for both negotiators.

- Reaching an agreement reflects that the negotiators succeeded in the negotiation process.

- Concluding the negotiation occurs after reaching an agreement, where the negotiators elevate their agreement and consider any enhancements. They might also talk about several matters that do not affect their agreement like its implementation.

Figure 1: Braun, et al. Negotiation Process Model

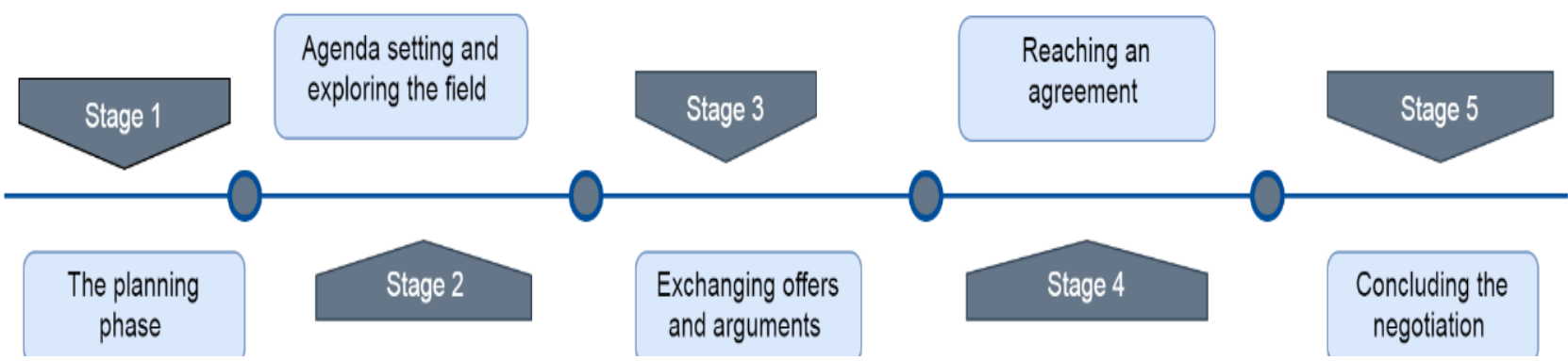

Source: Prepared by the author according to "e-Negotiation Systems and Software Agents: Methods, Models, and Applications", by Braun P. et al. process model, 2006, Intelligent Decision-making Support Systems.

Braun et al. (2006) negotiation process model is not specifically built for integrative negotiations. It is a general model, which considers the negotiation process from its planning step to finally reaching an agreement and concluding the negotiation, without aiming to reach win-win outcomes. However, integrative negotiations, which aim to create win-win outcomes, require specific activities and tasks to design or search for such outcomes. The following is an overview of negotiation theories with a detailed dive into theories that serve integrative negotiations, to build the specific negotiation process model related to integrative negotiations.

Overview of Negotiation Theories: Several decades ago, Zartman (1975) argued that there is no satisfactory theory to negotiation. Although the notion that negotiation is an art above conceptualization and skill beyond effective communication was contested effectively (de Callieres, 1983), (de Felice, 1975) and despite the fact that the work of Nash (1950), Rapoport (1966), Festinger (1957), and others has not been invalidated by unsuccessful application, Zartman (1975) demonstrates that negotiations are far resistant to theory because their dynamic pattern has not been fully apprehended. However, negotiation; with its interdisciplinary nature, comprises several theories. Different theoretical perspectives contribute to the development of the negotiation field and several theories contribute to defining and setting the process. Within the diversity of these theories, part of them serves to contribute to integrative negotiations. In 
addition, electronic media helps eliminate negotiation tricks that may take place in face-to-face negotiations (Croson, 1999). The following overview of negotiation theories breaks the theories to reach the ones that serve integrative negotiations and contribute to building the integrative negotiation process model.

From General Negotiation Theories to Integrative Negotiation Theories: Lande (2017) illustrates that negotiation theory includes several theoretical perspectives. The work of researchers and practitioners from various disciplines, who developed the field and its associated aspects, reflects the existence of the multiple theories that explain it (Alfredson \& Cungu, 2008). Negotiation theories could be prescriptive, descriptive, or normative in nature (Alfredson \& Cungu, 2008). In line with Alfredson \& Cungu (2008), Carnevale \& Pruitt (1992) explain three perspectives that the interest in negotiation has emerged from. The first, which provides advice to negotiators, like international negotiators in forming good agreements; is the prescriptive one. The second, which explores how negotiators should behave where mathematical theorists and economists used game theory; is the normative approach. Moreover, the third in which theorists consider how negotiators actually behave is the behavioral perspective. Moreover, and in addition to the different theories that explain the negotiation, theorists differ on how to categorize these theories. Druckman (1997) divided these theories into four negotiation approaches: "negotiation as puzzle-solving, negotiations as a bargaining game, negotiation as organizational management and negotiation as diplomatic politics". While Raiffa (1982) categorized them around the dimensions of "symmetry-asymmetry and prescription-description". Another form of dividing negotiation theories is offered by Zartman (1988), which comprises five different approaches: "the structural, the strategic, the processual, the behavioral and the integrative approaches".

These approaches either have roots in different theories or form the foundation of different theories (Alfredson \& Cungu, 2008). The structural approach is the theory where power is assumed as a central structural feature and the main determining mean in negotiations. It has its root in political theory. The strategic approach focuses on the ends rather than the means and negotiators are considered as rational decision-makers looking for a set of alternatives to maximize their own gains. It has its origins in mathematics, decision theory and rational choice theory. Strategic models are considered normative since they represent rational decision makers and search for the best solution in a negotiation. The strategic approach constitutes from negotiation theories such as game theory and critical risk theory. The integrative approach which frames negotiations as a win-win potential and parties give importance to information sharing and problem-solving has roots in international relations, political theory and social decision-making. Additional theoretical perspectives related to negotiation theory were presented by Lande (2017), including: identity theory, social interaction theory, field theory, human needs theory, rational choice theory, transformation theory and mutual gains theory. Identity theory "is a social psychological theory that attempts to understand identities, their sources in interaction and society.

Their processes of operation, and their consequences for interaction and society from a sociological perspective" (Burke \& Stets, 2009). It thus shapes negotiators' behavior according to society. Social interaction theory assumes that "peoples' social behaviors are determined by the social pressures they encounter. Behavior is partly created in response to our surroundings, specifically our social groups" (Muscato, 2019). Field theory is "an approach to understanding group behavior by trying to map out the totality and complexity of the field in which the behavior takes place" (Sundberg, Winebarger, \& Taplin, 2019). It focuses on pressure-producing psychological climates that affect negotiators' cognition and behavior. Human needs theory is a motivational theory in psychology developed by Maslow. It "illustrates the hierarchy of needs as a five-tier model often depicted as hierarchical levels within a pyramid. Needs lower down in the hierarchy must be satisfied before individuals can attend to needs higher up. From the bottom of the hierarchy upwards, the needs are: physiological, safety, love and belonging, esteem and self-actualization" (McLeod, 2018). Human needs theory asserts that every negotiator has biological and social needs driven by their emotions and values. The rational choice theory states "individuals rely on rational calculations and choose actions.

To achieve outcomes that are in line with their objectives and preferences. These decisions provide people with the greatest benefit or satisfaction given the choices available. It is used to model human decision making, especially in the context of microeconomics, where it helps economists better understand the behavior of a society in terms of individual actions as explained through rationality" (Amadae, 2016). Then, 
the rational choice theory assumes that negotiators' behaviors reflect choices driven by desires to maximize gains and minimize losses. Transformation theory analyzes how problems and disputes are actually transforming in the process of conflict. Mutual gains theory "focuses on the creation of value for all parties by creating options that meet all parties' interests and by using objective criteria to fairly divide gains". Negotiation can be seen as a challenging task where information disclosure about negotiators and their preferences helps to create more alternatives, thus increases the benefits to all parties and creates better results and good relationships (Knudsen , 2007). Mutual gains theory develops from rational choice and human needs theories and assumes that negotiators will reach an agreement because of the belief that reaching an agreement is better than not reaching an agreement (Spangle \& Isenhart, 2003).

Additional theoretical perspectives related to negotiation theory were presented by Lande (2017), including: "identity theory, social interaction theory, field theory, human needs theory, rational choice theory, transformation theory and mutual gains theory". Identity theory "is a social psychological theory that attempts to understand identities, their sources in interaction and society, their processes of operation, and their consequences for interaction and society from a sociological perspective" (Burke \& Stets, 2009). It thus shapes negotiators' behavior according to society. Social interaction theory assumes that "peoples' social behaviors are determined by the social pressures they encounter. Behavior is partly created in response to our surroundings, specifically our social groups" (Muscato, 2019). Field theory is "an approach to understanding group behavior by trying to map out the totality and complexity of the field in which the behavior takes place" (Sundberg, Winebarger, \& Taplin, 2019). It focuses on pressure-producing psychological climates that affect negotiators' cognition and behavior. Human needs theory is a motivational theory in psychology developed by Maslow. It "illustrates the hierarchy of needs as a five-tier model often depicted as hierarchical levels within a pyramid.

Needs lower down in the hierarchy must be satisfied before individuals can attend to needs higher up. From the bottom of the hierarchy upwards, the needs are: physiological, safety, love and belonging, esteem and selfactualization" (McLeod, 2018). Human needs theory asserts that every negotiator has biological and social needs driven by their emotions and values. Rational choice theory states "individuals rely on rational calculations and choose actions to achieve outcomes that are in line with their personal objectives and preferences. These decisions provide people with the greatest benefit or satisfaction given the choices available. It is used to model human decision making, especially in the context of microeconomics, where it helps economists better understand the behavior of a society in terms of individual actions as explained through rationality" (Amadae, 2016). Then, the rational choice theory assumes that negotiators' actions reflect decisions determined by wants to increase gains and decrease losses. Transformation theory analyzes how problems and disputes are actually transforming in the process of conflict. Mutual gains theory "focuses on the creation of value for all parties by creating options that meet all parties' interests and by using objective criteria to fairly divide gains".

Negotiation can be seen as a challenging task where information disclosure about negotiators and their preferences helps to create more alternatives, thus increases the advantages to all individuals and creates improved consequences and good relationships (Knudsen, 2007). Mutual gains theory develops from rational choice and human needs theories and assumes that negotiators will reach an agreement because of the belief that reaching an agreement is better than not reaching an agreement (Spangle \& Isenhart, 2003). Three main theories serve to build the automated integrative negotiation process model: Mutual gains theory, rational choice theory and decision theory. It is based on the idea of mutual gain and rational choice, in which negotiators cooperate to reach a win-win outcome. Mutual gains theory to create value and fairly divide gains so that both negotiating parties get satisfied with outcomes. And rational choice theory to rationally calculate and choose actions to achieve outcomes that are in line with the negotiators' objectives and preferences taking into consideration constraints present. Furthermore, decision theory helps to present a decision through a set of elements. The combined effect of these elements forms the outcome of a decision. Moreover, decision theory with mutual gains theory forms the negotiation process model that reflects the stages of the decision process. This process model ensures the development of a solution that is rational, fair and mutually satisfying. 
Decision Theory: Decision Theory is a theory about decisions. It has developed through contributions from several academic disciplines (Hansson, 1994). There is a clear division between researches from the various disciplines in the study of decision theory. For example, a political scientist studies the voting rules in elections whereas a psychologist studies the behavior of individuals. Most decisions are not momentary. They take time, and therefore several models are developed to reflect the different stages of a decision process. Several authors suggested that the stages of the decision process are sequential, while others indicate that they are performed in parallel and a more realistic decision model should allow these stages to come in a different order (Mintzberg, Raisinghani, \& Théorêt, 1976).

Stages of a Decision Process: The first general theory of the stages of a decision process was raised by the philosopher Condorcet (1743-1794). He split the decision process into three stages: (1) principles discussion as the first discussion, (2) detailed discussions and clarifications as to the second discussion, and (3) actual choice (resolution). Moreover, several sequential models contributed to modern decision theory. Dewey (1910) discussed that problem solving comprise five sequential stages: "(1) a felt difficulty, (2) the definition of the character of that difficulty, (3) suggestion of possible solutions, (4) evaluation of the suggestion, and (5) further observation and experiment leading to acceptance or rejection of the suggestion". Moreover, Herbert Simon (1960) adjusted Dewey's model to fit the circumstances of decisions in institutions. It consists of three principal stages: (1) intelligence, (2) design, and (3) choice. Another sequential model suggested by Brim et al. (1962) in which they split the decision process into five stages: "(1) identification of the problem, (2) obtaining necessary information, (3) production of possible solutions, (4) evaluation of such solutions, and (5) selection of a strategy for performance".

One of the most influential non-sequential models was suggested by Mintzberg, Raisinghani, and Théorêt (1976). They indicated that the decision process has separate stages but is not consecutive. They used the same stages of Herbert Simon but with different names: "(1) identification, (2) development, and (3) selection". The different phases comprise different routines. The identification phase has two routines, decision recognition in which the problem and alternatives are identified and the diagnosis in which present information channels and new ones are exploited to explain and state the issues. The development stage also comprises two routines. Search, which pursues to find ready-made solutions and design which develops new solutions modifies ready-made ones. Moreover, the selection phase consists of three routines. The screen routine in which suboptimal options are removed. The evaluation choice routine, which is the real choice between the alternatives. In addition, the last routine, authorization, where the solution selected is approved. The link between the phases and routines is circular rather than linear.

Figure 2: The Relationships between the Phases and Routines of a Decision Process, According to Mintzberg et al.

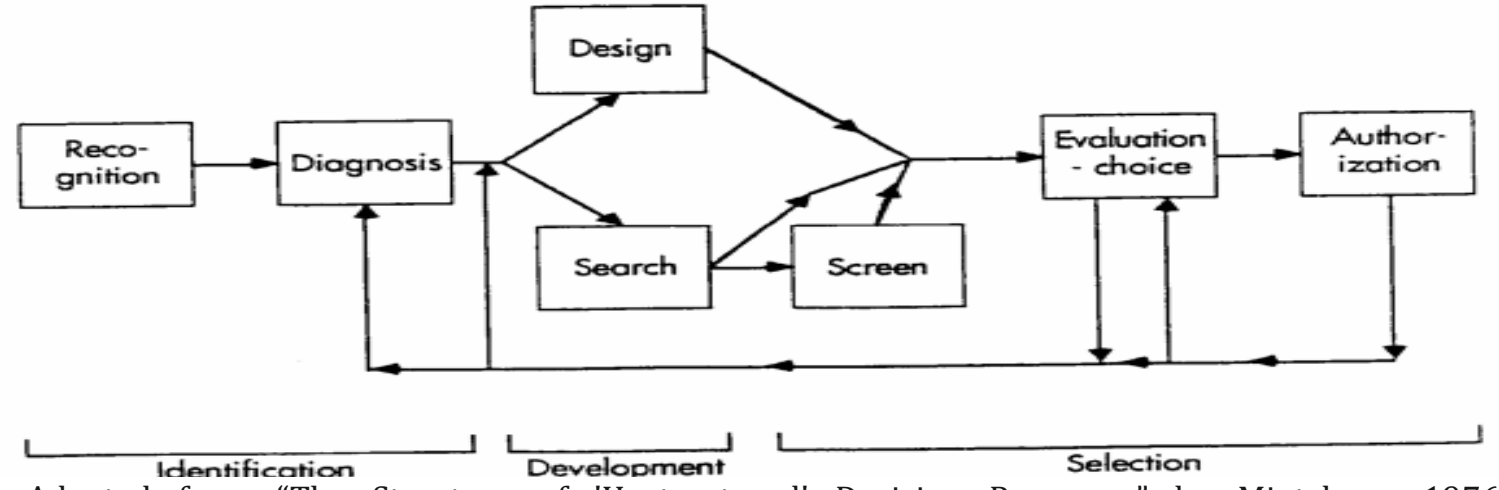

Source: Adapted from "The Structure of 'Unstructured' Decision Processes" by Mintzberg, 1976, Administrative Sciences Quarterly.

The three non-sequential phases suggested by Mintzberg, Raisinghani, \& Théorêt (1976) are key phases in the model, developed in this thesis. However, the routines are not reflected and the tasks of the phases are updated in line with other negotiation theories adopted. 
Representing the Decision Problem: A decision problem is expressed in a matrix format to reflect the multiple attributes contributing to the decision. The decision matrix consists of the valuations of the different alternatives according to the different criteria. Similarly, in decision theory, the evaluation-choice routine is represented in a matrix format. Decision theory uses the concepts alternative, outcome, and state of nature. Alternatives are options that are available to the decision-maker at the moment of the decision and from which he chooses. An outcome is the effect of the decision. The outcome relies on the decision maker's choice of an alternative and conditions outside of his power. Some of these conditions are recognized by the decision-maker, they are the background information he has. And others are unrecognized; they rely on how others behave and on characteristics of nature. Unknown factors are called "states of nature". Then, the potential outcomes of a decision are defined as "the combined effect of a chosen alternative and the state of nature that obtains". In a decision matrix, the alternatives available to the decision-maker are put in a table format with respect to the possible states of nature. The alternatives are resembled by the rows of the matrix, and the states of nature by the columns.

Table 1: Decision Matrix in Decision Theory

\begin{tabular}{lll}
\hline & State of Nature 1 & State of Nature 2 \\
\hline Alternative 1 & Outcome 1 & Outcome 2 \\
Alternative 2 & Outcome 3 & Outcome 4
\end{tabular}

Source: Done by the Author. For each alternative and each state of nature, the decision matrix assigns an outcome.

Figure 3: The Evaluation Choice Elements in Decision Theory

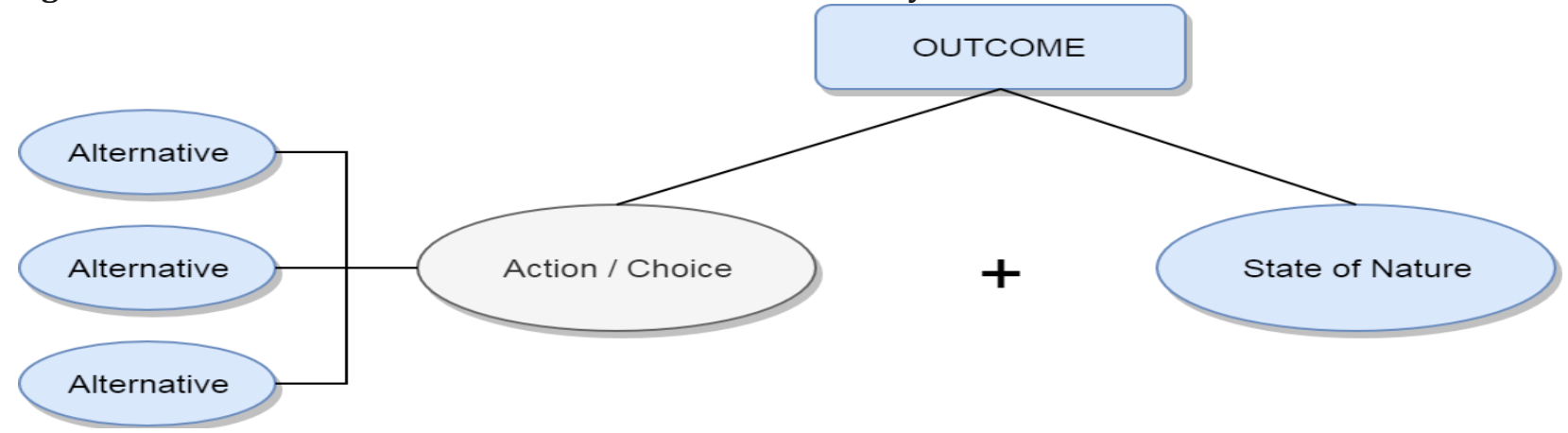

Source: Prepared by the Author according to Decision Theory

The notions of decision theory (i.e. alternative, outcome, and state of nature) that represent a decision are used in the thesis to symbolize the negotiation outcome as a result of the negotiators' choice from the different alternatives combined with the state of nature. In decision theory, there are different kinds of information about states of nature. When considering only one state of nature, the case will be decision making under "certainty". That is for each alternative, you know what will be the outcome. If not, then the case will be decision-making under non-certainty. Non-certainty is split into categories too: risk, uncertainty, and ignorance. Risk assumes that each action causes one set of potential outcomes, each outcome occurring with a specific probability. The probabilities are available to the decision-maker. While uncertainty assumes that the probabilities of outcomes are partially known. However, ignorance assumes that they are totally unknown. 
Figure 4: Types of Information in the Evaluation Choice

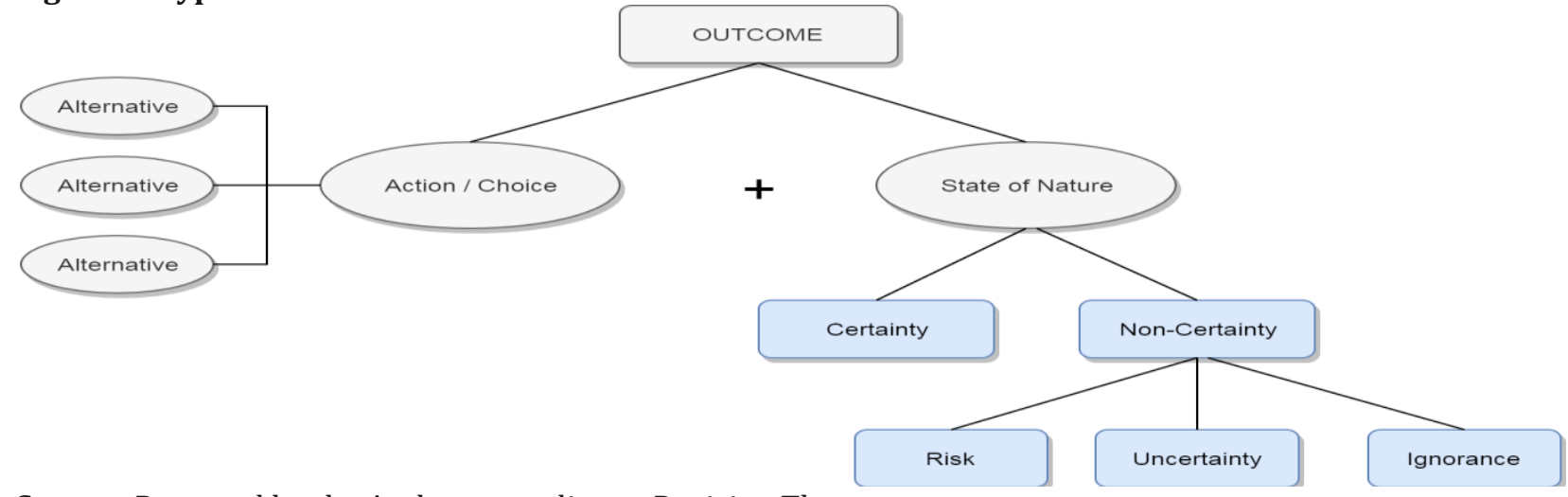

Source: Prepared by the Author according to Decision Theory

Rational Choice Theory: Rational choice theory holds a variety of models that explain the outcomes of rational individual actions. Rational behavior is "the behavior that is suitable for the realization of specific goals, given the limitations imposed by the situation" (Wittek, 2013). An individual's rational choice is explained through preferences, beliefs and constraints. Preferences resemble "individuals' positive or negative evaluations of outcomes" (Wittek, 2013). Preferences might stem from several origins. They might range from flavors of foods and customs that are transferred through cultures to individual-specific practices. Beliefs are the "perceived cause-effect relations, including the perceived likelihood with which an individual's actions will result in different possible outcomes" (Wittek, 2013). For example, a union head believes that a strike would help employees reach their demands. While constraints are "the limits to the set of feasible actions" (Wittek, 2013). For example, a salesperson sells items at the price range set by the company to maintain the competitiveness of the product. The basis of the rational choice theory refers to key assumptions now known as neoclassical economics.

The first considers individuals as selfish having selfish preferences, the second assumes each individual maximizes his utility, and the third assumes them acting independently. These were criticized which then led to the birth of "behavioral economics", which attempted to develop a more realistic behavioral foundation of the theory. Therefore, the editions of rational choice theory depend on the degree of adherence to the strict principles of the neoclassical model. Rational choice interpretations come in "thin" strictly neoclassical, versus "thick" sociological versions, in which these specific beliefs are lenient. They vary on three dimensions: "(i) the type of rationality, (ii) preference, and (iii) individualism" assumptions (Wittek, 2013).

(i) Rationality ranges from full rationality to bounded rationality and social rationality. Full rationality, the "thin" version of rational choice theory related to neoclassical economics, specifies that people are totally aware of the available options, the likelihood of each of their outcomes, and their related effects. Moreover, it argues that individuals are able to perceive and manage this information with no cognitive restrictions. Individuals evaluate alternatives based on cost-benefit equations and select the "alternative" with the greatest expected utility. However, bounded rationality assumes that the amount and kind of information are limited. Individuals get satisfied with "good enough" solutions rather than maximizing utilities. Moreover, social rationality, the "thick" model of rational choice theory, specifies how behavior is guided, either by gain-maximization as in the full or bounded rationality models or by other processes such as education or automatic answers.

(ii) Preferences vary between the different models of the theory. "Thin" models assume that preferences are known and stable where individuals tend to maximize their material gain. However, "thick" models assume that individuals may be motivated by social preferences and care for the well-being of others. They seek psychological or social gains and not only material ones. 
(iii) Individualism in all rational choice theory versions assumes that explanations of societallevel outcomes should be grounded in a micro-level behavioral theory of individual action. In the "thin" version, social structures are not relevant as restrictions on the action, however, in the "thick" versions, social and institutional embeddedness are considered as crucial conditions that influence individual decisions and behavior.

Figure 5: The Rational Evaluation Choice Elements integrated from Decision Theory and Rational Choice Theory

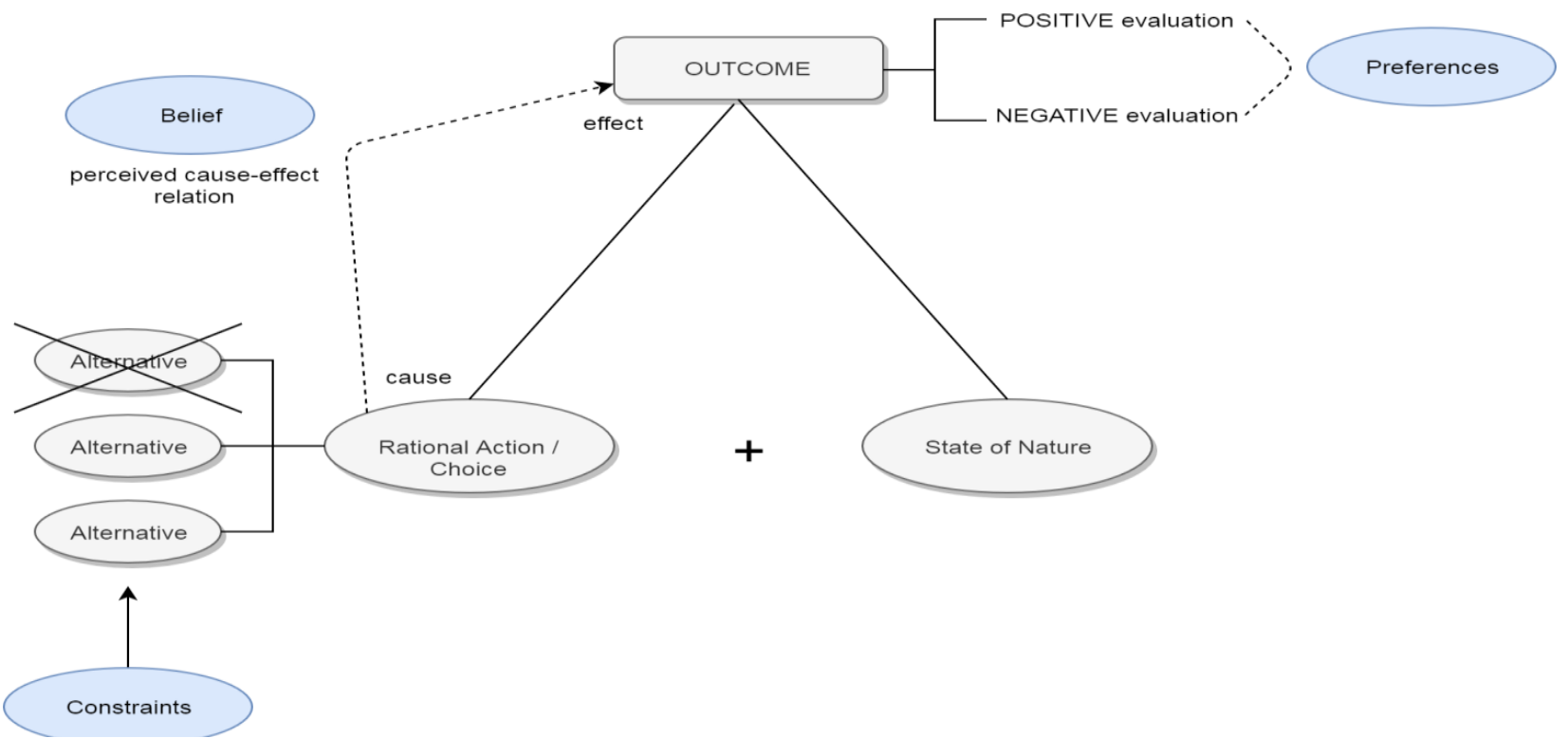

Source: Prepared by the Author according to Decision Theory and Rational Choice Theory

The factors that influence a rational choice set by rational choice theory (i.e. preferences, beliefs and constraints) contribute to identifying several variables in the model developed. Preferences serve to identify owns interests and the interests of others. While constraints serve to eliminate non-relevant or sub-optimal alternatives. Moreover, beliefs serve to form a probabilistic knowledge about the cause-effect relation between choice and outcome.

Mutual Gains Theory: The mutual gains approach (MGA) is a negotiation theory that is founded on the concept of value creation and then the fair distribution of this value based on objective criteria. This approach was well emphasized in the study of Howard Raiffa (1982), Roger Fisher and William Ury (1981). It suggests that negotiators should not be deceptive or aggressive to achieve their goals. Otherwise, they need to cooperate and contribute to the challenging process of value creation. MGA is a prescriptive process model that lays out four steps for negotiating better outcomes (Knudsen, 2007): "(i) preparation, (ii) creating value, (iii) distributing value, and (iv) follow-through".

(i) Preparation is about realizing owns interests and collecting information about counterpart's interests. These serve as the base for exploring and creating options and thus being able to find a mutually beneficial solution that satisfies both parties.

(ii) Creating value entails looking for mutually beneficial options, either by exploring these options or by developing them. For the process of creating value to be efficient, assessing and judging the options is deferred and negotiators never commit to any. It is a stage of the invention and never a commitment, where the parties attempt to enlarge the pie.

(iii) Distributing value relies on finding objective criteria that satisfy both parties and justify the fair share of the value created. The more options are created at the previous stage the easier distributing value becomes. Finding objective criteria, believing in them and using them, improves agreements' stability and increases individuals' satisfaction. Moreover, it increases the chances of effective implementation and protects relationships. 
(iv) Follow-through is about monitoring arrangements, which serve to reinforce the commitment to agreements. It is important to think of future challenges and solutions to them, but this might be difficult. Thus, monitoring commitments to agreements and regular communication preclude possible impediments and makes agreements robust.

Figure 6: The Negotiation Process Model in Mutual Gains Theory

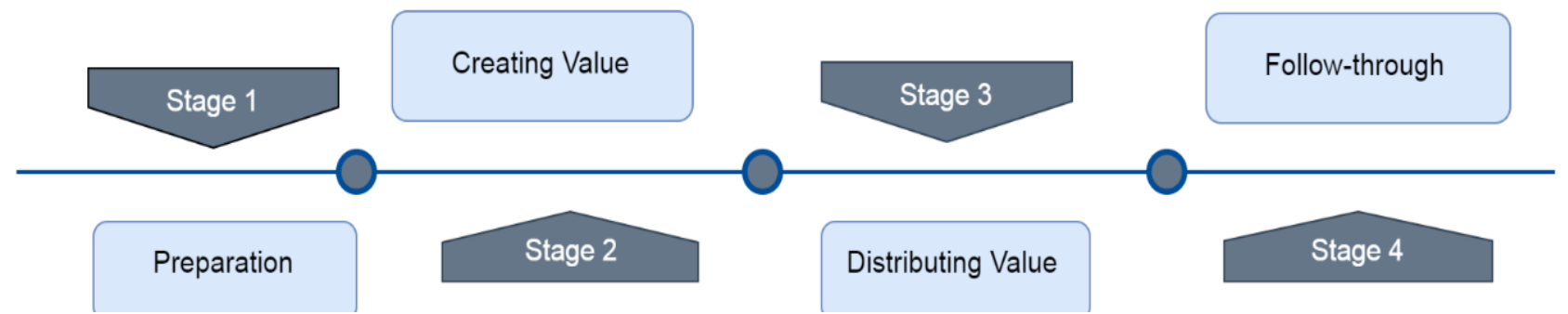

Source: Prepared by the Author according to Mutual Gains Theory

The value creation and distribution phases in mutual gains theory are fundamental steps in the development of a win-win outcome. The two phases are combined with the phases of decision theory to formulate a process model that maintains both theories' merits. Decision theory provides a robust process model and mutual gains theory ensures they are implemented in a fair, objective manner to come up with a satisfying win-win solution.

\section{Process Model Building}

Although there is no agreement in negotiation research regarding the negotiation process and whether it follows a specific sequence of stages (Lande, 2017), negotiation and specifically electronic negotiation requires a "process model" and a "protocol" (Kersten \& Lo, 2003). This process model should provide a structure to the negotiation through phases and activities assigned to them (Jennings, et al., 2001). Moreover, integrative negotiations entail specific tasks to create the desired win-win outcomes, which satisfy both negotiating parties. This negotiation process model is concluded and assembled from various models and theories that serve integrative negotiation approaches. The different theories share several similar phases, while they differ in others or the details of their activities. This model consists of five main phases.

Phase One "Identification": The negotiation process explained in decision theory and mutual gain theory initiates the negotiation by a planning phase. In decision theory termed as the "identification" phase, and in mutual gains theory as the "preparation phase". The model of this thesis uses the title "Identification" as in decision theory for the first phase of negotiation, but substitutes the two routines (recognition and diagnosis) of decision theory, with two activities from mutual gains theory: (i) realizing own interests and (ii) collecting primary information about others interests. However, instead of the regular collection of information about the opponent in the second activity, his utility model is attempted to be predicted. Therefore, the second activity of this phase would be (ii) predicting the opponent's utility model.

Phase Two "Exchanging Offers": The second phase of the model is "Exchanging Offers", which is selected from the Braun et al. model (2006). In Braun's model, exchanging offers allows negotiators to explore their counter parties' limitations so identifying areas of disagreement, compromises are realized, and solutions are restricted to efficient ones that are acceptable for both parties. These activities are shifted to different stages and are split between the subsequent phases. The main idea behind shifting these activities is the automation of the negotiation process. In a DSS like the one developed in this thesis, there exist, two main players, the negotiator and the negotiation agent, which is software that works behind the scenes and aids the negotiator in the negotiation procedure. Exploring counter parties' interests, identifying disagreement and restricting solutions to efficient ones are all tasks of the negotiation agent that are to be automated and optimized. Exchanging offers in this model is just about offering and counter offering, trying to reach an optimal solution. 
Phase Three "Development": The third phase of the model is one of the key phases. It is the "Development" phase. It consists of two main activities and several sub-activities within. The first activity is the "Identification" which is about (i) realizing own utility, (ii) realizing relationship utility and (iii) identifying disagreement. After receiving an offer, the negotiator assesses it, checks its profitability and values the relationship with the opponent. The second activity is "Creating Value" which is about (i) exploring or searching options and developing or designing new ones. The title of the development phase is from decision theory. The identification activity is the same essence as the first phase with some amendments where realizing relationship utility is developed under this thesis in an attempt of an adjustment to utility measurement. Moreover, the sub-activity identifying disagreement is adopted from Braun's et al. model and shifted from the exchanging offers phase to this phase. Moreover, creating value activity is adopted from mutual gains theory that contributes to the formation of a win-win solution. In this activity, an opponent negotiator receives an assessment of his previous offer, and accordingly creates a new offer attempting to reach the desired win-win outcome.

Phase four "Selection": The fourth phase of the model is the "Selection" phase. It is adopted from decision theory. The implementation of the phase is a combination of decision theory and mutual gains theory. It holds three activities, (i) screening, which is about eliminating suboptimal alternatives, (ii) distributing value, which is about finding objective criteria for option selection and gain splitting and (iii) evaluation choice, which is the real selection between the alternatives. Screening and evaluation choice are adopted from decision theory and distributing value is adopted from mutual gains theory.

Phase Five "Authorization": The last phase is about "Authorization". It is about approving the solution selected where both negotiating parties are satisfied and the solution is an optimal win-win solution that approves the hypothesis of the thesis. It is adopted from decision theory and shifted from the selection phase.

Synthesizing the Negotiation Process Model: Integrative negotiations, which aim to create win-win outcomes, use objective criteria, seek designing solutions of mutual gain, and give importance to exchanging information and group problem-solving. This model specifies the negotiation process in a set of phases and components that reflect the aim of integrative negotiations and building win-win outcomes. While the outcome, which is the effect of the decision is the result of the choice evaluation in the selection phase. In the development of the negotiation process model, decision theory with mutual gains theory provides a robust process model through several phases and rational choice theory with mutual gains theory ensures they are implemented in a fair, objective manner to come up with a satisfying win-win solution. Consequently, the relationship between the different variables is deduced from the negotiation theories, in a negotiation to come up with a win-win outcome, negotiators determine their preferences and counterparties collect information about states of nature. Then alternatives are designed along with the constraints formed from preferences and states of nature. The theories are used to complement each other to synthesize a negotiation process model that is used in integrative negotiations and leads to creating win-win outcomes. It consists of five phases with several activities and sub-activities that can be summarized as follows: Identification, Exchanging Offers, Development, Selection and Authorization. 
Figure 7: An Automated win-win Negotiation Process Model

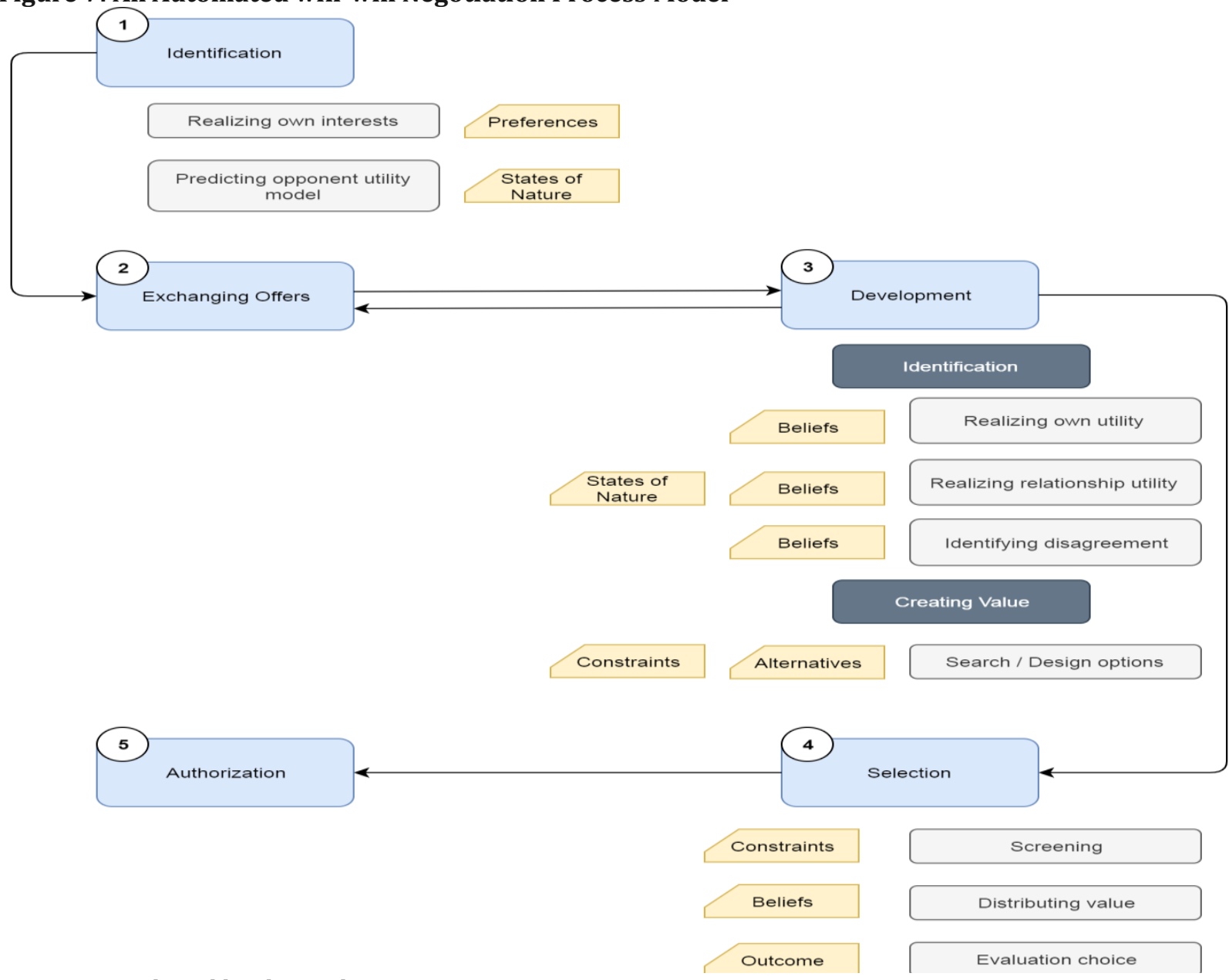

Source: Developed by the Author

The theories followed set several variables either to symbolize a negotiation outcome and reflect what composes it, or to determine a decision and how it is structured. Preferences, beliefs and constraints are variables from the rational choice theory that help to explain outcomes of rational individual actions (Wittek, 2013). Preferences that resemble "individuals' positive or negative evaluations of outcomes" (Wittek, 2013) are to be determined in the first negotiation phase of the model developed i.e. the identification phase. While beliefs which refer to "perceived cause-effect relations, including the perceived likelihood with which an individual's actions will result in different possible outcomes" (Wittek, 2013), are to be determined and used in the development phase in realizing own utility and relationship utility and in identifying disagreement as well as in the selection phase in distributing value. Furthermore, constraints which are "the limits to the set of feasible actions" (Wittek, 2013) are to be used in the development phase.

While searching and designing options and in the selection phase in screening. In addition, decision theory states some concepts to represent a decision. It uses alternatives, outcomes and state of nature. Alternatives, which are groups of options present to the decision-maker at the moment of the decision and from which he chooses, are to be specified in the development phase in creating value. The states of nature, which are the factors outside of the decision-maker's control and are unknown to him, are to be determined in the identification and development phases while predicting the counter parts' utility model and then assessing relationship utility. Finally, beliefs drive choice to a desirable outcome. The process model serves to create win-win negotiation outcomes through its defined phases and components that reflect integrative negotiation approaches, through identifying negotiators' needs, identifying disagreement, creating value through designing and searching for alternatives, and distributing value. 


\section{Results and Discussion}

Negotiation research diverges regarding the negotiation processes whether they are defined and structured or not. However, electronic negotiation requires a "process model" and a "protocol" (Kersten \& Lo, 2003) to be able to implement and run the process. Braun et al. (2006) process model defines and organizes a process model for negotiation phases. However, this model is generic and applies to all negotiation approaches. The fact that the integrative negotiation approach gains clear advantages over the other approaches in which the outcome reached is win-win and satisfying for both negotiating parties entails building a different negotiation process model. A process model that is more specific and adheres to the integrative approach principles so that outcomes reached are mutually profitable as the approach aims. The negotiation process model proposed in this paper implements the integrative negotiation approach principles through its phases and activities. It starts with the "Identification" phase in which negotiators exchange information, which is a principle in integrative negotiations that leads to transparency. Then in the "Development" phase, identifying disagreement and then creating value through searching and designing options is another aspect of integrative approaches. Furthermore, in the "Selection" phase, offers are assessed and value is distributed among the negotiators in an objective manner, which along with the "Development" phase leads to a win-win outcome. The phases and the principles integrated into them serve to create negotiation alternatives and enlarge the value that is evaluated and distributed in an objective manner. Therefore, the automated negotiation process model as a whole eliminates subjectivity, manages the negotiation process in a cooperative manner and designs the negotiation outcome objectively and mutually satisfying the parties engaged in which both gains are considered.

\section{Conclusion}

With the advancement of technology, automated negotiation gained clear advantages whether in trade, economic or political aspects. This paper develops an automated negotiation process model for integrative negotiations in which the negotiators aim to reach mutually satisfying win-win outcomes. It defines the phase and sub-phases that constitute the model. Furthermore, it determines the components of the phases, which help analyze the negotiation situation and create the solution. Among all negotiation theories, three main theories contribute to building the process model specific to integrative negotiations: Decision Theory, Rational Choice Theory and Mutual Gains Theory. The theories share several similar phases, while they differ in others or the details of their activities. In the developed model, decision theory with mutual gains theory provides the robust process model through several phases, and rational choice theory with mutual gains theory ensures they are implemented in a fair, objective manner to come up with a satisfying win-win solution. The foundation of the negotiation process model contributes to the development of the negotiation field in which no previous models are found for automated integrative negotiations. As electronic negotiation gained clear advantages and integrative negotiation approaches outperform the other approaches, then building a negotiation process model that is automated and adheres to the integrative approach principles is considered a step forward.

\section{References}

Alfredson, T. \& Cungu, A. (2008). Negotiation Theory and Practice: A Review of the Literature. FAO.

Amadae, S. M. (2016). Rational Choice Theory. From Britannica: https://www.britannica.com/topic/rationalchoice-theory

Arunachalam, V. \& Dilla, W. N. (1995). Judgment Accuracy and Outcomes of Negotiation: A Causal Modeling Analysis of Decision-aiding Effects. Organizational Behavior and Human Decision Processes, 61, 289304.

Braun, P., Brzostowski, J., Kersten, G., Kim, J. B., Kowalczyk, R., Strecker, S. \& Vahidov, R. (2006). e-Negotiation Systems and Software Agents: Methods, Models, and Applications. Intelligent Decision-making Support Systems, 271-300.

Burke, P. J. \& Stets, J. E. (2009). Identity Theory. New York: Oxford University Press. From Oxford Scholarship Online.

Carmel, E., Herniter, B. C. \& Nunamaker, J. F. (1993). Labor-management Contract Negotiations in an Electronic Meeting Room: A Case Study. Group Decision and Negotiation, 2, 27-60. 
Carnevale, P. J. \& Pruitt, D. G. (1992). Negotiation and Mediation. Annual Review of Psychology, 43, 531-582.

Croson, R. T. (1999). Look at Me When You Say That: An Electronic Negotiation Simulation. Simulation and Gaming, 30, 23-37.

de Callieres, F. (1983). On the Manner of Negotiating with Princes. Paris, France: University of Notre Dame Press.

de Felice, F. B. (1975). Negotiations, or the Art of Negotiating. New York: Doubleday Anchor.

Drolet, A. L. \& Morris, M. W. (2000). Rapport in Conflict Resolution: Accounting for How Face-to-Face Contact Fosters Mutual Cooperation in Mixed-Motive Conflicts. Journal of Experimental Social Psychology, 36, 26-50.

Druckman, D. (1997). Negotiating in the International Context, in Peacemaking in International Conflict: Methods and Techniques. Washington DC: United States Institute of Peace Press, 81-124.

Festinger, L. (1957). A Theory of Cognitive Dissonance. New York: Row Peterson.

Fisher, R. \& Ury, W. (1981). Getting to Yes. United Kingdom: Penguin Group.

Fisher, R., Ury, W. \& Patton, B. (1991). Getting to Yes: Negotiating Agreement Without Giving In. Revised 2nd edition. New York, USA: Penguin Books.

Gifford, D. G. (2007). Legal Negotiation: Theory and Practice. St. Paul, MN: Thomson/West.

Gulliver, P. H. (1979). Disputes and Negotiations: A Cross-cultural Perspective. New York: Academic Press.

Hansson, S. O. (1994). Decision Theory. Stockholm: Royal Institute of Technology.

Jennings, N. R., Faratin, P., Lomuscio, A. R., Parsons, S., Wooldridge, M. J. \& Sierra, C. (2001). Automated Negotiations: Prospects, Methods and Challenges. Group Decision and Negotiation, 10(2), 199-215.

Kersten, G. E. \& Lo, G. (2003). Aspire: Integration of Negotiation Support System and Software Agents for EBusiness Negotiation. International Journal of Internet and Enterprise Management, 1(3), 293-315.

Knudsen, L. K. (2007). Trust and Mutual Gains Approach: Negotiations Between Westerners and Chinese. Bergen: Norwegian School of Economics and Business Administration.

Lande, J. (2017). Taming the Jungle of Negotiation Theories. The Negotiator's Desk Reference, Research Paper No. 2017-29.

Lewicki, R. J., Barry, B., Saunders, D. M. \& John, M. W. (2003). Negotiation, 4th edition. Irwin: McGraw-Hill.

Lewicki, R. J., Saunders, D. M. \& Barry, B. (2015). Negotiation. New York, NY: McGraw-Hill Education.

McLeod, S. (2018). Maslow's Hierarchy of Needs. From Simply Psychology: https://www.simplypsychology.org/maslow.html

Mintzberg, Raisinghani, D. \& Théorêt, A. (1976). The Structure of 'Unstructured' Decision Processes. Administrative Sciences Quarterly, 21, 246-275.

Muscato, C. (2019). Social Interaction Theory, Social Roles \& the Presentation of Self. From Study.com: https://study.com/academy/lesson/social-interaction-theory-social-roles-the-presentation-ofself.html

Nash, J. F. (1950). The Bargaining Problem. Econometrica, 18(2), 155-62.

Raiffa, H. (1982). The Art and Science of Negotiations. Belknap Press of Harvard University Press Cambridge.

Rapoport, A. (1966). Two-person Game Theory. Ann Arbor: University of Michigan Press.

Spangle, M. L. \& Isenhart, M. W. (2003). Negotiation: Communication for Diverse Settings. CA: SAGE Publications, Inc.

Sundberg, N. D., Winebarger, A. A. \& Taplin, J. R. (2019). Clinical Psychology: Evolving Theory, Practice, and Research (4th Edition). United States: Pearson. From KB Manage: https://www.kbmanage.com/concept/field-theory

Wittek, R. (2013). Rational Choice Theory. In R. L. Warms, \& J. R. McGee, Theory in Social and Cultural Anthropology - An Encyclopedia (p. 1056). USA: SAGE Publications, Inc.

Zartman, I. (1988). Common Elements in the Analysis of the Negotiation Process. Negotiation Journal, 4, 3143.

Zartman, W. (1975). Negotiations: Theory and Reality. Journal of International Affairs, 29, 69-77. 